\title{
Money and Mental Contents
}

\author{
Sarah Vooys \& David G. Dick \\ University of Calgary \\ savooys@ucalgary.ca \\ dgdick@ucalgary.ca
}

\begin{abstract}
It can be hard to see where money fits in the world. Money seems both real and imaginary, since it has obvious causal powers, but is also, just as obviously, something humans have just made up. Recent philosophical accounts of money have declared it to be real, but for very different reasons. John Searle and Francesco Guala disagree over whether money is just whatever acts like money, or just whatever people believe to be money. In developing their accounts of institutions as a part of social reality, each uses money as a paradigm institution, but they disagree on how institutions exist. Searle argues that the institution of money belongs to an ontological level separate from the physical world, held up by the collective intentions of a group, while Guala claims that money is a part of the ordinary physical world and is just whatever performs a "money-like function" in a group, regardless of what that group believes about it. Here, we argue that any purely functional account like Guala's will be unable to capture the distinctive phenomenon of money, since monetary transactions are defined by the attitudes transactors hold toward them. Money will be obscured or misidentified if defined functionally. As we go on to show by examining recent work by Smit et al., belief in money does not require taking on all of Searle's ontological commitments, but money and mental contents will stand or fall together.
\end{abstract}

\section{Keywords:}

money, natural kinds, social kinds, intentionality, institutions, ontological commitment, social ontology, social objects 


\section{Money and Mental Contents}

\section{Introduction}

It is hard to see where money fits in the world. Money has obvious causal powers: it can allow or prevent people from doing all sorts of things. But just as obviously, money is a human invention, something we just made up, and it is something that would disappear if we stopped holding up its existence. Money therefore seems to have claims on being both real and imaginary, both factual and fictitious.

This paper does not aim at settling the questions of exactly where money fits in the world and whether we ought to believe in it or not, but it does aim to make some progress on both of those questions. It argues that money is ineluctably connected to the existence of the intentional attitudes of creatures with minds, since monetary transactions only occur when objects are exchanged for the sake of their exchange value. Any attempt to show that money is part of the real and actual world must be able to capture this.

Any explanations of distinctively monetary phenomena in the world that deny the existence of, or that are indifferent to the attitudes agents hold toward those phenomena cannot succeed because they exclude a crucial constitutive feature of what makes money money. Whether this means we ought to believe in money or not is a separate question. All we wish to establish here is that money and mental contents will stand or fall together, at least in one direction, since there can be no adequate account of money that does not allow for mental contents as well.

This mental contents constraint will have consequences for recent philosophical work on money. Specifically, it will exclude Francesco Guala's recent attempts to define money in purely functional terms. Guala makes the claim that money is a part of the ordinary physical world and 
is simply whatever performs a "money-like function" in a group, regardless of what that group believes about it. Guala's account is a response to John Searle's account of money as a part of what he calls "institutional" reality that depends on a group's "collective intentions" toward it in order to exist. Roughly, Guala tells us that money is whatever acts like money, while Searle claims that money is whatever people believe to be money.

Our primary aim in this paper is to establish one necessary condition for any descriptively adequate account of money. We apply this condition to recent accounts of money as an institutional object in the literature on social ontology. In presenting this debate, we will describe Searle's account of money first, so that it will be easier to see in the next section how Guala's account is meant as a response to it. In section four, we draw a distinction between transactions, which include the reason for an exchange, and exchanges, which do not, and use this distinction to argue that money can only be captured in terms of distinctive transactions. Section five then argues that Guala's is an account of mere exchanges, not transactions, and so cannot be an adequate account of money. In section six, we investigate what sort of ontological commitments belief in money therefore involves and argue that one need not be a Searlean in order to be a realist about money, as recent work by Smit, Buekens, and Du Plessis (hereafter Smit et al.) shows. In the seventh section, we observe that attending to the mental contents constraint makes two further contributions to the debate about institutional reality and social ontology. First, it provides a different way to configure the debate, with some authors and their critics landing on the same side. Second, it draws attention to an underappreciated way in which social objects depend on propositional attitudes for their existence. In our final section, we conclude by indicating what this teaches us about the reality of money and its place in the world. 


\section{Searle on Money}

According to John Searle (1995), money is an institution. For Searle, institutions are remarkable things because, while they are created by humans out of subjective attitudes like beliefs and intentions, we can still make objectively true statements about them. By distinguishing between the ontological and epistemological aspects of institutions, Searle is able to claim that institutions are ontologically subjective, because they depend on human attitudes for their existence, yet epistemically objective, because we can make objectively true or false claims about them.

Epistemically objective statements, according to Searle (2005), are "true or false independently of the feelings and attitudes of the makers and interpreters of the statement." (p. 4) Institutions allow for such epistemic objectivity because they are built from a group's collective intentionality. Intentional attitudes are directed mental states and encompass desires, beliefs, intentions, etc. These attitudes occur in our minds individually, yet there can be collective intentionality when two or more agents intend something together, or in "we" terms. Both humans and many species of animals have the capacity for collective intentionality, and this intentionality is the basis of all social reality (Searle, 2005, p. 6). A wolf pack hunting a deer is operating with collective intentionality, just as two people exchanging wedding vows are operating with collective intentionality. The wolves intend together to hunt the deer, instead of being a random collection who just happen to coalesce in a simultaneous attack on it. The couple getting married intend together to behave toward each other in particular ways, instead of merely saying words in a ceremony and then hoping their individual projects will thereafter happen to 
coincide. In each case, the parties intend to do something together, and each is an instance of collective intentionality thereby creating social facts (i.e. any fact involving the collective intentionality of two or more agents) about which epistemically objective claims can be made. Even if Sally is a part of the group collectively intending a social fact into existence, that social fact does not depend on Sally's feelings and attitudes alone, and so she, independently of her individual attitudes, can make claims about those social facts that can be right or wrong, and so epistemically objective.

Institutions, subsets of social facts, require collective intentionality, but unlike the case of social facts, this intentionality is not sufficient for creating institutions. Searle distinguishes institutional facts from social facts by an imposition of function. We have the capacity to impose functions on objects, for instance assigning a log the function of being a chair. Here, the $\log$ functions as a chair through a combination of an agent's intentions and the log's own physical properties - it wouldn't be a chair if the agent hadn't intended it to be one. But agents can impose functions in another way, independent of an object's physical characteristics. This assignment is called a status function, a function that can only be performed because the power to do so is collectively assigned. Where a row of logs can perform the physical function of being a barrier, a line of paint on the ground would make a useless barrier unless it is granted the status function of a boundary that is not to be crossed.

An institution results from collective intentionality and the assignment of a status function and is described as $X$ counts as $Y$ in context $C$ (Searle, 2005, p. 7). The $\mathrm{X}$ term identifies a certain feature (or an object, person, state of affairs etc.); the $\mathrm{Y}$ term is the assignment of a special status to the $\mathrm{X}$; the $\mathrm{C}$ term specifies the context in which the assignment takes place. Searle refers to these as constitutive rules, because they create, or constitute, the things they 
govern. When a line of paint is assigned the status of 'boundary,' the boundary is simultaneously created and described.

Money is a paradigm institution for Searle. Paper money is created when people collectively intend some piece of paper (X) to count as money (Y) in a certain social group (C). By so doing, they give the piece of paper the status it needs to function as a medium of exchange, unit of account, and store of value, which it can now do in virtue of this assignment alone. The word 'money' itself is unnecessary; rather, what matters is the publically accessible idea that some $\mathrm{X}$ counts as a unit of account, medium of exchange, and store of value (Searle, 1995, pp. 63-71). Because money operates through the assignment of a status function, it does so when people collectively intend for some $\mathrm{X}$ to be their medium of exchange, not when something is exchanged for the value of its physical characteristics. This does not mean that things with valuable physical properties cannot be exchanged as money. Searle (2005) points out that often institutional facts evolve out of natural ones (p. 11). Money could evolve out of something that was once seen as having value by virtue of its physical properties rather than by virtue of its assigned status. But it is only when people start to view the thing as something that can be used to exchange due to its collectively assigned status that we have the institution of money.

\section{Guala on Institutions}

According to Searle, money as a social kind is constructed at least partly out of the subjective attitudes of agents. Nevertheless, it is open to investigation by social scientists and others, because epistemically objective claims can be made about it. The reality described by the social sciences is, however, "totally unlike the reality described by physics and chemistry," and 
Searle insists that social scientists must understand the ontology they study before they can even establish their methodology, let alone predict and explain phenomena. (Searle 2005, p. 1)

Guala disagrees both with Searle's claims about methodology and his claim that social reality must be built out of collective intentionality.

Methodologically, Guala (2015) insists that "ontology is not and can never be prior to science" (p.11). By denying that ontology must come first, Guala opens up social reality to scientific investigation beyond what Searle's theory will allow. Social kinds have causal features akin to other scientific kinds, and thus we can study them and make predictions about them, precisely like the predictions of chemical or physical phenomena. What this means is that social kinds possess describable causal properties, which can be used for prediction and explanation without reference to any group intentions. Since collective intentionality is unnecessary to capture social reality, institutions should be thought to consist in the stable, predictable, and describable behaviour patterns of a group, rather than in its deliberate collective intentions.

Amie Thomasson (2003) has already observed that not all social facts depend on collective intentionality to exist. For example, an economy can be in a recession even if no one in that economy intends it to be, and a society can be racist even if no member of it notices that it is (and would even deny the allegation that it was) (p. 606). Thomasson's argument leaves open the possibility that all institutions still rest on collective intentionality, even if not all social facts do. Guala extends Thomasson's argument to show it is also true that not all institutions depend on collective intentionality, using the racist institution of apartheid. Apartheid, argues Guala, "did not rest on a collective agreement or a group intention: the whole point of apartheid in fact was to undermine the notion that black and white people belonged to the same community." (Guala 2016, p. 108) Social and institutional objects like these are able to exist independently of 
the collective intentionality Searle insists is necessary for them, and so serve as counterexamples to Searle's view.

Since collective intentionality is unnecessary when explaining parts of social reality such as institutions, Guala sets out to show how an institution can be derived without it. ${ }^{1}$ Guala (2016) sees institutions as solutions to coordination problems, where rules are imposed that result in an overall outcome better than the one that would have occurred if everyone acted independently. This he calls a "rules-in-equilibrium" approach (p. xxv).

Instead of using Searlean constitutive rules in the form ' $\mathrm{X}$ counts as $\mathrm{Y}$ in $\mathrm{C}$,' Guala uses a rule-based game theory approach in the form 'if X then do Y.' In circumstances in which the best overall outcome does not occur through people acting unilaterally, there is a coordination problem. If each person acts independently, an overall worse outcome is achieved. In these circumstances, rules of the form 'if $\mathrm{X}$ do $\mathrm{Y}$ ' can be imposed, and in following these rules, a better outcome is achieved.

Since these rules are imposed in circumstances where the best outcome is achieved through people not acting unilaterally, this means there must be some sort of incentive for people to follow the rules. The incentives could be negative or positive. For example, in the case of money, a particular metal might come to be money because it has advantageous qualities such as portability, imperishability, divisibility and recombinability. Alternatively, the government could impose a tax that can only be paid for in the new currency of salt. If people do not pay their taxes in salt, the government will punish them. In either case, people are incentivized to use this new

\footnotetext{
${ }^{1}$ In tandem with his necessity argument, Guala (2010) also argues that collective intentionality is insufficient for deriving institutions - if people collectively believe something is money but it fails to function as such, collective acceptance is insufficient to create that institution. However, since Searle never claims that collective acceptance is sufficient for institutions and our mental contents constraint leaves aside questions of what is sufficient for social objects like money, we opt not to address Guala's sufficiency argument outside this footnote.
} 
currency as money, regardless of their belief about it. Both the institution of money itself and the particular form of currency arise not out of a group's deliberate collective intentions, but rather out of a set of pressures and incentives. Therefore, people do not need to view the new currency as money, they simply must use it as money (i.e. in an exchange, as a store of value, a unit of account). This means that for something to be considered money, the intentions of the people exchanging it do not matter, what matters is that it is functioning in an exchange. An outside observer, such as a social scientist, can determine that something is money, regardless of what the people using it believe about it. Since money, like all social institutions, is a pattern of behaviour in response to incentives, it can be predicted and described just like any other natural phenomenon, using the ordinary methods of science. Money and other social institutions need not be considered "totally unlike the reality described by physics and chemistry." (Searle 2005, p. 1)

On Guala's (2016) account, money is not what we collectively agree to be money, it is instead whatever fulfills the various functions of money. It can be anything from shells to electronic bytes (p. 35). "The existence of money does not depend on the representation of some things as money, but on the existence of causal mechanisms that ensure that some entities perform money-like functions" (Guala 2015, p. 9). These functions include serving as a medium of exchange, a store of value, and a unit of account. The term money is not dependent on the representation of some things as money, but rather is dependent on the actions associated with it, actions like "accept as payment" (Guala 2015, p. 10). For Guala, money is whatever acts like money, regardless of the reason why. 


\section{Exchanges and Transactions}

Both Searle and Guala are only indirectly interested in money. They are instead concerned with institutional reality more generally and disagree primarily over the role that collective intentionality plays in it. For each of them, money serves as a paradigm of institutional reality, not an independent object of investigation. Nonetheless, we can still evaluate their contrasting accounts of money to see how well they describe the phenomenon of money. Doing so will reveal not only an important feature of money, which any adequate account of it will have to capture, but also a different axis of disagreement among Searle, Guala, and other authors working on institutional reality. To do this, we begin by considering the relationship between money and exchange value.

Monetary transactions are distinctive, different from other transactions. When something is exchanged as money, it is given or accepted on the strength of its exchange value. When someone accepts a five-dollar bill as money, they accept it for its capacity to be exchanged for other things. When they are happy to take the five-dollar bill as payment because they know they can use it later to trade for other things they need or want, it is the bill's exchange value that they recognize and are moved by. This is different from accepting the five-dollar bill for some other reason corresponding to the many other uses the bill can have. If someone instead accepts the bill because it makes a lovely bookmark, is just the right colour scheme to hang in their house as a decoration, or to use as kindling in a fire, then the transaction rests on the bill's use value, and is a barter object, not a piece of money.

The observation that monetary transactions are about exchange value is hardly new. Aristotle condemned usury since "money was intended to be used in exchange, but not to increase at interest." (McKeon 1941, p. 1141) He similarly condemns the practice of "retail" 
(investing money in commodities to later sell for more money) because it treats the means of exchange (i.e. money) as an end. Arguably, the very telos of money on Aristotle's analysis of it, is to facilitate exchange (Meikle 1994, p. 34).

David Hume (1907) considered money as "only the instrument which men have agreed upon to facilitate the exchange of one commodity or another... it is the oil which renders the motions of the wheels more smooth and easy" (p. 309). Similarly, Adam Smith claimed "money is the known and established instrument of commerce, for which everything is given in exchange" (1976, p. 438).

Marx put the point even more vividly, claiming that whenever a commodity functioned as money it "congealed" into "the only adequate form of existence of exchange-value, in opposition to use-value, represented by all other commodities" (Marx 1867, p. 84). Marx's theory of the alienation of commodities states, "when they assume this money-shape, commodities strip off every trace of their natural use-value...” (1867, p. 74). In fact, according to Marx, when gold functions as money it becomes the "embodiment of value" and "is exchange-value itself" (Marx 1867, p. 72). Marx even goes to the trouble of explicitly contrasting this with the use-value of gold which is just "the sum of the various uses of gold" (Marx 1867, p. 72).

Trading something as money involves a transaction that rests on exchange value, while trading it for its use value counts as barter. Distinguishing these two sorts of transactions in this way is neither controversial nor new but has important implications that can be clarified by using a distinction drawn from action theory.

Christine Korsgaard distinguishes an "act" from an "action," by claiming that "an action ... involves both an act and an end, an act done for the sake of an end" (Korsgaard 2009, p. 11). An act can be fully captured by describing what is done, while an action can only be captured by 
describing both what is done and why it is done. This allows the same act to be part of two very different actions. Korsgaard's distinction allows us to see how driving a mile south to get ice cream and driving a mile south to flee the scene of a hit and run are two different actions containing the same act. It also allows us to see how Kant need not contradict himself when he condemns a suicide committed to avoid future personal misery, but not a suicide performed to prevent harm to others when one has been bitten by a rabid dog. (Korsgaard 2009, p. 11) In both of these cases, the very same act forms part of two different actions, distinguishable because the same act is done for the sake of two different ends.

We can draw an analogous distinction between exchanges and transactions. Just as the same act might form part of different actions, the same exchange can form part of different transactions. As described above, the exchange of a five-dollar bill can be part of a monetary transaction or a barter transaction, depending on the sake for which the bill is exchanged. When the bill is exchanged for the sake of its exchange value, it is money, as observed by philosophers from Aristotle to Marx. But when the very same bill is exchanged —even between the same people for the same good or service - for its use value, it is not money, and is instead a barter object inside a barter transaction. What is crucial to notice here is that what is distinctive about monetary transactions, and what distinguishes those transactions from barter and all other sorts of exchange, are the reasons or motives of the agents involved in those transactions. ${ }^{2}$ In short, a

\footnotetext{
${ }^{2}$ Objects can have both use value and exchange value simultaneously and agents can appreciate both kinds of value simultaneously, so there is no reason to suppose that a single transaction could not be done for the sake of both use and exchange value at the same time. For example, one might buy a painting both because it is beautiful and as an investment. It is an interesting further question whether such a transaction counts as money, barter, both, or neither. As we have seen above, Marx would not classify this transaction as a monetary one, because he says money strips off "every trace of ... use value..." (Marx 1867, p. 74) But, for purposes of this paper, we take no position on precisely how much a transaction must be done for the sake of exchange value to count as money, since our claim is only that a transaction cannot be a monetary one unless it is at least partially about exchange value. How much it must be about exchange value is an interesting, but separate, question. (Thanks to an anonymous reviewer for help in clarifying this point.)
} 
necessary part of what makes something a monetary transaction are the details of the mental contents of the agents engaged in the transaction. In order for an exchange to count as money inside a distinctively monetary transaction, agents must have not only intentional content about it, but intentional content of a distinctive sort. Perhaps this intentional content can be dispositional or subconscious, not readily coming to mind or easily articulated by the agents who have it, but it must be about the object's exchange value, or done for the "sake" of its exchange value, as Korsgaard would put it, if the exchange is to count as a monetary transaction.

Being about exchange value may not be sufficient to make a transaction a monetary one. Other distinctive features of money might still be identified and argued for as additionally necessary for an adequate account of money, but we restrict ourselves here to arguing only for this mental constraint on accounts of money. As we will show in the following section, the mental contents constraint will exclude Guala's recent attempt to capture money in purely functional terms. This does not, however, mean that we must commit all accounts of money to Searlean collective intentionality, as we demonstrate in section six. Then, in section seven, we show that when considering social objects subject to a mental contents constraint, two new aspects of the debate become clear: the first is the way that authors on opposite sides of the debate over collective intentionality can still be on the same side of the mental contents constraint, and the second is an important and different way in which a social object can depend on an attitude with a particular content. 


\section{Against Functionalism about Money}

Since monetary transactions are just those exchanges made for the sake of exchange value, we will be unable to capture or distinguish them if we cannot identify the sake for which some agent agrees to an exchange.

This is where a purely functional account of money like Guala's will fall short. Guala's understanding of the institution of money explicitly "does not depend on the representation of some things as money, but on the existence of causal mechanisms that ensure that some entities perform money-like functions" (Guala 2015, p. 9). This will mean that it will classify anything performing a "money-like function" as money, whether it is performed for the sake of the object's exchange value or not, and so it will mistakenly identify as money cases of sufficiently sophisticated barter and any other externally indistinguishable pattern of exchange regardless of the intentional content of the agents involved.

Consider three cases.

In the first, a group uses gold to perform a "money-like function," exchanging it for goods and services in a familiar way. For this case, let us stipulate that the gold is money, because all the agents involved in exchanging it do so for its exchange value. If asked, they would honestly respond that what's good about the gold how well it works as a medium of exchange: everyone recognizes that the gold is valuable because it can be traded for whatever else one might want.

In the second case, let all the behaviours of the group remain constant, but change the reason for these exchanges to now rest on the use value of gold. In this case, when the agents are asked why they are so happy to exchange gold, they would honestly reply "Who doesn't like gold? It's shiny, it makes lovely jewelry and fountain pen nibs; why, you can even fix your teeth 
with it! Who wouldn't be happy to get some gold?" In this case, even though the nature of the exchanges has not changed, the nature of the transactions has. Since these exchanges are all done for the sake of the use value of the gold, they are instances of barter, and the gold that changes hands is a barter object, not money.

Finally, consider a case identical to the two above in terms of the externally observable behaviour, but stipulate that all the behaviour is performed for reasons having nothing to do with either the use or exchange value of the gold. When these agents are asked, they would reply "This gold is a gift from the gods to bring us good luck. To receive some gold from someone is a great honor, and politeness demands anyone receiving some gold express their gratitude with a gift of some valuable good or service. The more gold received, the greater the honor, and so the greater the gift such politeness demands."3

But because all three cases involve gold performing a "money-like function," Guala's account will classify them all as instances of the institution of money. This is the danger in advancing a purely functionalist account of money, one that "does not depend on the representation of some things as money," as Guala does. (Guala 2015, p. 9) It will classify anything that acts like money as a full monetary transaction. But this, we argue, is a mistake, since monetary transactions are transactions of a distinctive kind, done for the sake of the exchange value of the object exchanged. Any purported account of money indifferent to the sake for which an exchange occurs will be unable to properly capture distinctively monetary phenomena, and risks misclassifying, as Guala's account will, cases of barter, religious practice,

\footnotetext{
${ }^{3}$ Though it is hard to see what larger function such a group would have and what coordination problem it would solve, we could also imagine an externally identical pattern of exchanges performed by mindless automata that have no mental contents at all. Here, it is not even clear that these exchanges can be classified as any sort of transaction at all, because the beings doing the exchanging have no "sake" for which they exchange. In Korsgaard's terms, these beings merely "act," performing no "actions" at all. (Thanks to an anonymous referee for help clarifying this point.)
} 
superstition, or exchanges done with any other motivation as genuine monetary phenomena instead. $^{4}$

\section{Money and Ontological Commitments}

By insisting that monetary transactions are about exchange value, and that any proper account of money must therefore include some account of the attitudes or other specific mental contents of the agents involved in them, we might seem to be encouraging some readers to abandon the phenomenon of money altogether. By rejecting Guala's account of money that is designed to make it a part of the ordinary world of scientific investigation, we might be understood to be claiming that belief in money involves a commitment to an additional ontological level that is "totally unlike the reality described by physics and chemistry." If that is so, we might be better off disposing of money altogether. If belief in money requires further belief in collective intentions and all the other apparatus Searle invokes to explain social reality, some physicalists and minimalists might conclude that that is simply too high a price to pay, that we must instead deny money as a distinctive phenomenon, and settle for a world that contains exchanges, but no transactions.

While we do claim that money and mental contents must stand or fall together, we do not take any position in this paper concerning what the proper account of these mental contents must be, other than to insist that they be capable of capturing monetary transactions as being about exchange value. Whether this is to be done with attitudes, dispositions, or whatever else and

\footnotetext{
${ }^{4}$ Because Guala's account is indifferent to the sakes for which exchanges occur, it is also incapable of giving a proper account of barter, since barter transactions are those that occur for the sake of the use value of the objects involved. An account indifferent to all reasons for which agents might transact or represent those transactions to themselves will be unable to capture both money and barter.
} 
whether such things are ultimately physical or irreducibly mental are both questions beyond the scope of this paper. This is why we have chosen the more encompassing term 'mental contents,' rather than committing to a specific position about beliefs, desires, reasons, attitudes, dispositions, and so on. Our goal here is to establish that anyone wishing to give an adequate account of money must be able to capture what monetary transactions are distinctively about, not to evaluate the various attempts that might be made to respectably explain that aboutness. As far as this paper goes, we do not even insist that readers must include money in their ontology, whatever the other considerations might be. However, if someone does accept money into their ontology, they need not accept all of Searle's claims in order to capture what money is about. Fortunately for us, we need not gesture at the mere possibility of accounting for the aboutness of monetary transactions in a non-Searlean way, since recent philosophical work on money gives us a detailed account of what one such possibility might look like.

Across a series of recent papers, Smit et al. advocate an account of money similar to Searle's, but capable of ontologically reducing collective intentions into nothing more than incentives, which themselves are reducible to nothing more than beliefs and desires (Smit et al. 2011, p. 4). One's own specific ontological commitments will determine whether this reduction is enough to make Smit et al.'s account of money acceptable, but for our purposes it is illuminating because it shows in detail how the mental contents constraint can be met without taking on all of Searle's own ontological commitments. When the debate is considered in light of the mental contents constraint rather than in terms of collective intentionality, we find Searle and Smit et al. on the same side. While their accounts differ precisely on the necessity of collective intentionality for institutional reality, they both provide accounts of money that capture the way 
it rests on a distinctive kind of attitude, namely the way monetary transactions must be done for the sake of exchange value.

According to Searle's theory, money, and all other institutions will not only be irreducibly subjective, they will involve commitment to another ontological primitive in the subjective world: collective intentionality. While they do not object to all subjective things, Smit et al. reject collective intentions as ontological primitives, and work to show how they are not irreducible after all. They ask "is the Searlean apparatus of collective intentionality leading to irreducibly institutional facts at all necessary for understanding things like money, borders, etc.?" (2011, p. 3). They seek to show it is not necessary by explaining institutional facts using actions and incentives, rather than collective intentions and status functions. They change Searle's formulation of "X counts as $\mathrm{Y}$ in $\mathrm{C}$," to "S is incentivized to act in manner $\mathrm{Z}$ towards $\mathrm{X}$." If they can derive the same institutions from incentives and action, then they show Searle's purported primitive to be reducible after all.

Smit et al. claim that agents can act so as to incentivize others to act in given ways. Through punishments and rewards, or threats and promises of the same, agents can provide incentives to other agents to act in particular ways (Smit et al. 2011, p. 13-14). Sometimes, when the incentivization is stable enough, a social fact results (Smit et al. 2011, p. 8). "The difference between a single case of being incentivized in a certain way, and a situation where the incentivization is strong enough, widespread and durable enough to amount to an institutional fact, is a mere statistical difference" (Smit et al. 2011, p. 10). Where Searle sees a difference in kind between collective intentions and mere collections of individual intentions, Smit et al. see a only a difference of degree. A social fact or institution is nothing more than a set of individual intentions that has stabilized into a recognizable shape. Some ontologically subjective things are 
required to do this, like intentions (which themselves are just beliefs and desires) but explaining institutions, according to Smit et al., requires nothing more than that.

Some things, like houses and hamburgers, provide incentives by virtue of their physical properties. The way they are physically constituted is closely linked to our reason for acting. We have a reason to eat a hamburger because it offers nourishment. Other things, like institutions, also involve a close link between reason and action, but not because of their physical nature. For institutions the "full incentivization needs to be brought about by some human action, or moral belief, that serves to incentivize us" (Smit et al, 2016, p. 1816). In both cases we have a reason, but one comes from the physical properties of an object and the other comes from agents creating incentives (p. 1816). People can be incentivized by others to act in a certain way, and when such incentivization is stable enough, the resulting pattern is a 'social fact' (Smit et al, 2011, p.8). An institutional object is simply a natural object individuated by these actions and incentives, an " $\mathrm{X}$ that $\mathrm{S}$ is incentivized to act in manner $\mathrm{Z}$ towards" (Smit et al. 2011, p.7) As long as people can attach incentives to natural objects, institutional objects can exist (Smit et al, 2016, p. 1816).

One such incentive, could, of course, be a group of people coming together and deliberately assigning a status to some thing, in a way that Searle would describe as collective intentionality assigning something a status function. Smit et al. do not set out to deny that people can intend together and thereby give one another reasons to act, only that such collective intentions are necessary for institutions or social facts, or that such collective intentions are ontologically primitive, irreducible to something more familiar (Smit et al. 2014, p. 1826).

How does money work on the incentivized view? People must be incentivized to begin using something as money. The source of the incentives does not matter, just that the appropriate incentives have been created (Smit et al. 2011, p. 14). For example, one person could start to use 
mackerel tins as the new currency. They might start collecting them because they are so durable, which could lead them to "acquire them with the intention of exchanging rather than consuming them." Eventually, other people begin to do the same. At some point, this behavior is so widespread that the mackerel tins become money, but "the tins of mackerel 'being money' is no more than the sediment of a simple practice that has stabilized" (Smit et al. 2014, p. 1827).

At this point, it might be unclear how Smit et al.’s account of money, specifically, could be considered an improvement over either Searle's or Guala's. It is built out of ontologically subjective elements, such as incentives, beliefs, and desires, and declares itself to be explicitly uninterested in how these incentives come about, caring only that they do. This would seem to be taking on nearly all of Searle's ontological commitments, as well as Guala's indifference to content, thereby taking on the drawbacks of each view and the virtues of neither.

This appearance is misleading. Smit et al.'s account of money does indeed commit itself to beliefs and desires, which Searle would classify as irreducibly ontologically subjective, but neither they nor we must join Searle in his commitment to the irreducibility of subjective entities like beliefs and desires. The point of their project is to show that, even in the set of entities Searle classifies as irreducibly subjective, some purported primitives can be reduced to other entities. Smit et al. readily admit that actions and incentives are mind-dependent, but only as far as they require beings with minds to exist. Whether or not subjective entities are reducible to objective entities, Smit et al. work to show that even among the subjective entities, there are workable accounts of money that are more ontologically austere than Searle claims are possible.

Furthermore, their reliance on incentives, beliefs, and desires allows their building blocks to accommodate the mental contents condition we argue is necessary for an adequate account of money. As we have claimed, monetary transactions must be about exchange value in order to 
truly count as monetary, and while Smit et al. are indifferent as to how the relevant incentives create the institution of money, they are always careful to specify that these incentives must be about exchange.

For example, they describe money as "an object that we are incentivized to acquire for exchange, rather than for direct consumption" (Smit et al. 2014, p. 1818, emphasis added). They (2016) tell us that "as soon as a commodity is adopted as 'money', a group of people who previously had no reason to acquire it suddenly have a reason to acquire it," because those who had no use for it before can now use it to exchange for things they can use (p. 343). Their most recent paper gives a definition of money which is complex, yet still fundamentally about exchange value. According to them, money is something that is "typically acquired in order to realise the reduction in transaction costs that accrues in virtue of such agents coordinating on acquiring the same thing when deciding what thing to acquire in order to exchange" (p. 331).

By explaining money in terms of incentives that can accommodate the content monetary transactions must have, Smit et al. provide an account of money that can successfully meet the mental contents constraint, while also appealing to fewer ontological primitives than Searle's account does. It therefore meets our condition for adequacy and fulfils their goal of providing an account involving fewer ontological primitives than Searle's.

\section{Social Objects, Collective Intentions, and Propositional Attitudes}

The debate in the literature is generally organized around the question of collective intentionality. Searle is on one side, while all those who deny the necessity of collective intentionality are on the other. This division has acted as a distraction from other important 
factors in the debate. ${ }^{5}$ While Searle and Smit et al. differ on the importance of collective intentionality for institutional reality, they both provide accounts of money in which money is about exchange value, as our mental contents constraint requires. One way in which this aboutness can be understood is as a propositional attitude.

By focusing on the propositional attitude required for money rather than on collective intentionality as the axis of disagreement, we find that the sides of the debate have changed. On one side is Guala, unable to capture social objects that are subject to a mental contents constraint, and on the other are Searle and Smit et al., whose views accommodate social objects which depend on propositional attitudes with specific contents.

Muhammad Ali Khalidi (2015) also uses propositional attitudes to categorize social kinds. He divides them into groups depending on the extent to which they require propositional attitudes for their existence. Like Khalidi, we rely on propositional attitudes; however, we are focusing on propositional attitudes of a different sort, and this difference is important. ${ }^{6}$ When Khalidi discusses the propositional attitudes on which social objects might depend, he means, quite precisely, propositional attitudes about those social objects themselves. Khalidi is interested in the question of whether social kinds like racism, war, money, and prime minister depend for their existence on people having attitudes toward those very social kinds themselves. Khalidi (2015) even defines the term "attitudes" in his paper "to stand in for propositional attitudes or mental states that explicitly represent the kinds in question.” (p. 98)

\footnotetext{
${ }^{5}$ Thanks to an anonymous reviewer for help in clarifying this point.

${ }^{6}$ This does not mean we disagree with Khalidi's classification of money. Khalidi (2015) classifies money as a distinctive social kind, whose existence depends on at least some members of a group having attitudes toward the type 'money,' but which does not require that those attitudes be held toward every token of that type, in order to make them an instance of that kind. Our mental contents constraint neither includes nor excludes Khalidi's account of money. Khalidi's account of money requires attitudes directed toward the type 'money,' while our constraint requires specific attitudes in every instance of money. They are in principle compatible, and together might constitute jointly necessary conditions on money.
} 
Khalidi's view reveals a kind of representationalism, one that insists at least some social kinds, institutions, or other social objects depend on attitudes about those kinds, institutions, or objects in order to exist. It is this representationalism which Guala (2015) denies when he claims money "does not depend on the representations of some things as money." (p. 9) The debate regarding the role that propositional attitudes play in institutions has so far been focused on the propositional attitudes about those institutions themselves. ${ }^{7}$ We propose a shift of focus, to a propositional attitude with a different kind of content. In the case of money, the relevant attitudes are not those directed at the kind or institution 'money' itself, but rather those directed toward the objects in the exchange. If the exchange is sufficiently about exchange value, it will count as a monetary transaction.

Money therefore depends on attitudes for its existence, but not on attitudes regarding the institution of money itself, with which the debates over collective intentionality and propositional attitudes have usually been concerned. Social objects that depend on a propositional attitude in the way money depends on attitudes toward exchange will thwart any purely functional attempts to capture them. The mental contents constraint introduced here both divides the debate on the social ontology of institutions in a different way, placing authors traditionally understood as opponents on the same side as allies, and shows that there is another,

\footnotetext{
${ }^{7}$ A recent exchange between Searle (2015) and Hindriks and Guala (2015) in the Journal of Institutional Economics covered a variety of issues, but also included a disagreement over the importance of what Hindriks and Guala call "the very human capacity to represent rules." $(2015$, p. 517) Searle insists a rule cannot possibly be normative without the humans representing the rule to themselves as authoritative, while Hinkriks and Guala claim a rule can be normative without such explicit representation. This debate is also about propositional attitudes directed at social objects themselves, because it is essentially about whether a rule must be explicitly recognized as having its status in order to be normative (which is to say it depends on some attitudes directed toward it in order to exist) or if a rule can be normative without such explicit recognition (which is to say it does not depend on the attitudes directed toward it).
} 
importantly different, way in which a social object can depend on a propositional attitude to exist, a way that has so far been underappreciated in the debate. ${ }^{8}$

\section{Conclusion}

The mental contents constraint introduces one necessary requirement for any adequate account of money, and demonstrates a previously underappreciated way in which a social object can depend on a propositional attitude. As far as accounts of money go, whether or not one considers Smit et al.'s account of money as an improvement over Searle's will, of course, depend also on one's other ontological and methodological commitments. Relative to our mental contents constraint alone, both Searle and Smit et al.'s accounts of money succeed, but we do not here assert that meeting this single necessary condition is sufficient to vindicate either their accounts of money specifically or of social reality more generally. Indeed, someone might find both accounts to involve too many unacceptable ontological commitments to endorse. As far as this paper is concerned, we have no quarrel with anyone wishing to discard the accounts of Searle, Smit et al., and any other account which includes intentional mental contents in the world.

We would object if that person declined those ontological commitments and yet went on to assert that while the world has no mental contents, it nevertheless has money. As we have argued in this paper, that can't be, because money is about exchange value, and no one who discards this aboutness can capture money.

\footnotetext{
${ }^{8}$ We are not the first to notice that social objects can depend on propositional attitudes this way. Thomasson (2003) asserts and Khalidi (2015) agrees that social kinds like racism, inflation, recession, and poverty all depend on some propositional attitudes to exist, but not on attitudes about those kinds themselves. Thomasson and Khalidi both notice that this sort of social object is possible, but do not make any larger use of this fact.
} 
Here, we have objected to Francesco Guala's recent attempts to explain money without accounting for the intentional mental contents of the agents using it. We argue that in doing so, Guala gives an inadequate account of money. This is not to say either that Guala's account of money is beyond repair, or that money must be the model for all social reality. The details of the social object in question will determine whether it is also subject to a mental contents constraint in the way that money is. Guala (2016) himself discusses other institutions like marriage and private property. If those social kinds are found to also depend in the same way on the mental contents of the agents creating them, then Guala's attempts to capture them in terms of pure function will also fall short. Perhaps these institutions do depend on mental contents in the way money does (perhaps marriage has to be about love and private property about greed), but settling those questions are projects involving the large and sophisticated literatures on them, and well beyond the scope of this paper.

Within its scope has been an investigation of three prominent accounts of institutional reality through their ability to capture distinctively monetary phenomena. Because money is a matter of transactions, rather than mere exchanges, accounts like Searle's and Smit et al.'s can capture it because they can capture the mental contents in which money partially consists. By contrast, Guala's current model of social reality cannot capture any social object like money that requires not only that creatures with minds bring it into existence, but that those minds hold specific attitudes toward it in order to make it what it distinctively is.

Whether this ultimately makes money real or imaginary, factual or fictitious, remains to be seen, and requires further argument. We do, however, hope to have made some progress toward answering these questions by showing in this paper that, wherever money fits in the 
world, it must be in the same category as mental contents, because it cannot be what it is without them.

\section{Acknowledgements}

Thanks for their help in the preparation of this paper are due to Marc Ereshefsky, Ann Levey, and audiences at meetings of both the Western Canadian Philosophical Association, and the Philosophy, Politics, and Economics Society. The authors would also like to thank two anonymous reviewers at Synthese for their constructive and useful feedback on the paper. One reviewer in particular gave our manuscript extraordinarily detailed and sympathetic attention, and we are especially grateful for all their diligence and care.

\section{References}

Guala, F. (2010). Infallibilism and Human Kinds. Philosophy of the Social Sciences, 40(2), 244264.

Guala, F. (2015). Philosophy of the Social Sciences: Naturalism and Anti-naturalism. The Oxford Handbook of Philosophy of Science.

Guala, F. (2016). Understanding institutions: The science and philosophy of living together. Princeton University Press.

Hindriks, F., \& Guala, F. (2015). Institutions, rules, and equilibria: a unified theory. Journal of Institutional Economics, 11(3), 459-480. 
Hindriks, F., \& Guala, F. (2015). Understanding institutions: replies to Aoki, Binmore, Hodgson, Searle, Smith, and Sugden. Journal of Institutional Economics, 11(3), 515-522.

Hume, D. (1907). Essays: Moral, political, and literary (Vol. 1). Longmans, Green, and Company.

Khalidi, M. A. (2015). Three kinds of social kinds. Philosophy and Phenomenological Research, 90(1), 96-112.

Korsgaard, C. M. (2009). Self-constitution: Agency, identity, and integrity. OUP Oxford.

Marx, K. (1867). Capital, volume 1. Retrieved from https://www.marxists.org/archive/marx/works/download/pdf/Capital-Volume-I.pdf

McKeon, R. (Ed.). (1941). The basic works of Aristotle. Modern Library.

Meikle, S. (1994). Aristotle on money. Phronesis, 39(1), 26-44.

Searle, J. R. (1995). The construction of social reality. Simon and Schuster.

Searle, J. R. (2005). What is an institution? Journal of institutional economics, 1(1), 1-22.

Searle, J. R. (2015). Status functions and institutional facts: reply to Hindriks and Guala. Journal of Institutional Economics, 11(3), 507-514.

Smit, J. P., Buekens, F., \& Du Plessis, S. (2011). What is money? An alternative to Searle's institutional facts. Economics and Philosophy, 27(01), 1-22.

Smit, J. P., Buekens, F., \& Du Plessis, S. (2014). Developing the incentivized action view of institutional reality. Synthese, 191(8), 1813-1830.

Smit, J. P., Buekens, F., \& Du Plessis, S. (2016). Cigarettes, dollars and bitcoins-an essay on the ontology of money. Journal of Institutional Economics, 12(2), 327-347. 
Smith, A. (1976). An Inquiry into the Nature and Causes of the Wealth of Nations, 1st edn 1776, vol. II of The Glasgow Edition of the Works and Correspondence of Adam Smith, edited by RH Campbell, AS Skinner and WB Todd. AS Skinner and WB Todd.

Thomasson, A. L. (2003). Realism and human kinds. Philosophy and phenomenological research, 67(3), 580-609. 